\title{
Layer-by-layer Assembly of Prussian Blue and Carbon Nanotube Composites with Poly(diallyldimethylammonium chloride) for the Sensitive Detection of Hydrogen Peroxide
}

\author{
Jian LI,*** Yanli YAO,** and Kwok-Keung SHIU**† \\ *Institute of Analytical Science, Shaanxi Provincial Key Laboratory of Electroanalytical Chemistry, \\ Northwest University, Xi'an, Shaanxi 710069, P. R. China \\ **Department of Chemistry, Hong Kong Baptist University, Kowloon Tong, Kowloon, Hong Kong, P. R. China
}

\begin{abstract}
Prussian blue (PB) was deposited on multi-walled carbon nanotubes (MWCNT) in an aqueous solution. Multi-layer composites of the MWCNT-PB hybride material were obtained by layer-by-layer assembly with poly(diallyldimethylammonium chloride) (PDDA). The resulting $\{\text { PDDA/MWCNT-PB }\}_{\mathrm{n}}$ multilayer films immoblized on glassy carbon electrodes showed sensitive detection for the reduction of hydrogen peroxide. A sensor based on the $\{\text { PDDA/MWCNT-PB }\}_{\mathrm{n}}$ multilayer structure was fabricated and showed excellent sensitivity to the electrochemical reduction of hydrogen peroxide. Its response sensitivity increased with the number of the multilayers. A high response sensitivity of $0.83 \mathrm{~mA} \mathrm{M} \mathrm{m}^{-1} \mathrm{~cm}^{-2}$ was obtained for a seven-layer sensor. This redox active multilayer structure offers potential applications in the development of high performance biosensors and biofuel cells.
\end{abstract}

(Received December 9, 2009; Accepted January 25, 2010; Published April 10, 2010)

\section{Introduction}

Carbon nanotubes (CNT), consisting of cylindrical graphene sheets with nanometer diameters, combine in a special way with unique physicochemical properties. ${ }^{1-4}$ In recent years, CNT have been proved to be a potential material for future nanodevice applications, such as nanoprobes, bioelectronics and

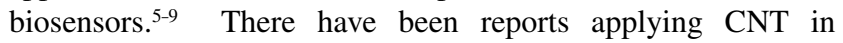
electrochemical catalysis of $\mathrm{H}_{2} \mathrm{O}_{2}$ and $\mathrm{O}_{2}$ through lowering the overpotentials of electrode processes. ${ }^{10,11}$ Due to their good electric conductivity and unique physicochemical properties, the applications of functionalized CNT composites have also been explored. CNT coated with various metal particles such as Pd, $\mathrm{Pt}$ and Pt-Ru have been synthesized and used as high-performance electrocatalysts toward oxygen reduction and methanol oxidation. ${ }^{12-14}$ Zhang and Gorski ${ }^{15}$ observed a synergetic effect in the oxidation of $\beta$-nicotinamide adenine dinucleotide (NADH) when both CNT and redox mediators were employed. They suggested that the introduction of CNT in the polymer matrix containing redox mediators offered improvements in the electronic transport and ionic transport in the polymer film.

Electrodes modified with Prussian blue (PB) usually showed excellent electrocatalytic activity toward the reduction of hydrogen peroxide. ${ }^{16-19}$ To realize these applications, electrodes immobilized with high amounts of active components with good stability are usually required. The deposition of PB on various substrates through electrochemical and photochemical means have been reported. ${ }^{20-22}$ When $\mathrm{PB}$ was electrochemically deposited on gold electrodes modified with CNT/poly(4-

$\dagger$ To whom correspondence should be addressed.

E-mail: kkshiu@hkbu.edu.hk vinylpyridine) (PVP) composites, a synergistic effect for the reduction of hydrogen peroxide was observed. ${ }^{22}$ Hydrophobic and other intermolecular interactions between CNT surface and PVP resulted in the formation of a stable CNT/PVP composite. ${ }^{23}$ Recently, there have been several reports integrating $\mathrm{PB}$ and CNT for hydrogen peroxide detection. ${ }^{24-26}$

In this report, a simple procedure for the deposition of $\mathrm{PB}$ on the sidewalls of multi-walled carbon nanotubes (MWCNT) is explained. The resulting MWCNT-PB composite was used as a building block for the fabrication of multilayer structures on glassy carbon electrodes by the layer-by-layer technique. ${ }^{27-31}$ Multilayer assemblies of MWCNT-PB composites were obtained by alternative dipping the electrode in separate solutions containing positively charged poly(diallyldimethylammonium chloride) (PDDA) and negatively charged MWCNT-PB composites. The multi-layered film showed sensitive detection for the reduction of hydrogen peroxide. The amount of MWCNT-PB deposits can be easily controlled, and the resulting material affects the sensitivity of the detection. This approach can be applied for the construction of high-performance biosensors and biofuel cells.

\section{Experimental}

\section{Chemicals and reagents}

Multi-walled carbon nanotubes were purchased from Nanoport Co. Ltd. (Shenzhen, China), and were treated in a 1:3 (v:v) mixture of concentrated $\mathrm{HNO}_{3}-\mathrm{H}_{2} \mathrm{SO}_{4}$ at $50^{\circ} \mathrm{C}$ for $24 \mathrm{~h}$. The CNT materials were then thoroughly washed with doubly distilled water. The functionalized MWCNT materials were obtained by drying in vacuum at $70^{\circ} \mathrm{C}$ overnight. PDDA with a molecular weight range of $200000-350000$ was purchased 
from Aldrich and was used as received. All other chemicals were of analytical reagent grade and were used without further purification. Aqueous solutions were prepared with doubly distilled water.

\section{Instrumentation}

All electrochemical measurements were carried out by a BAS-100BW electrochemical analyzer (Bioanalytical Systems, Inc., USA) in a conventional three-electrode arrangement, and the analyzer was equipped with a platinum wire counter electrode, a $\mathrm{Ag} \mid \mathrm{AgCl}$ reference electrode and a glassy carbon (GC) working electrode. All potentials were quoted versus the $\mathrm{Ag} \mid \mathrm{AgCl}$ reference electrode.

The surfaces of GC electrodes were characterized by scanning electron microscopy (SEM) with an LEO-1530 scanning electron microscope (LEO Electron Microscopy Inc., Cambridge, UK) operated at a $20-\mathrm{kV}$ accelerating voltage. UV-visible spectra were recorded using a Cary UV-100 UV/Vis spectrophotometer (Varian). The absorbance of the MWCNT-PB multilayer films assembled on quartz slides was measured. Each quartz slide was treated with freshly prepared piranha solution (a 1:3 mixture of $30 \% \mathrm{H}_{2} \mathrm{O}_{2}$ and concentrated $\mathrm{H}_{2} \mathrm{SO}_{4}$ ) and was then washed in pure ethanol and water before use.

\section{Preparation of the MWCNT-PB composite}

A $10-\mathrm{mg}$ portion of treated MWCNT material was dispersed in $10 \mathrm{~mL}$ of water. The suspension was agitated in an ultrasonic bath for $20 \mathrm{~min}$. The black MWCNT suspension was mixed with an acidic solution containing $1 \mathrm{mM}$ potassium ferricyanide and $\mathrm{Fe}\left(\mathrm{NO}_{3}\right)_{3}$ in $0.1 \mathrm{M} \mathrm{KCl}(\mathrm{pH} \mathrm{1.6)}$ in a sonication bath for $30 \mathrm{~min}$. The resulting mixture was allowed to stand for $8 \mathrm{~h}$. The resulting MWCNT-PB composite was collected by high-speed centrifugation, followed by thorough washing with doubly distilled water.

\section{Preparation of $\{P D D A / M W C N T-P B\}_{n}$ multilayer films}

A GC electrode of $3.0 \mathrm{~mm}$ in diameter (Bioanalytical Systems Inc.) was mechanically polished to a mirror finish progressively with 0.3 and $0.05 \mu \mathrm{m}$ alumina on wet microcloth (Buehler). The electrode was then rinsed with doubly distilled water and cleaned in a sonicating bath for $5 \mathrm{~min}$ followed by further rinsing. The electrode was activated by cyclic voltammetry between -0.3 and $+2.0 \mathrm{~V}$ in $0.5 \mathrm{M} \mathrm{H}_{2} \mathrm{SO}_{4}$ at $0.1 \mathrm{~V} / \mathrm{s}$ until stable voltammograms were obtained. ${ }^{32}$ Layer-by-layer (LbL) self-assembly of PDDA and MWCNT-PB composite, designated as $\{\text { PDDA/MWCNT-PB }\}_{\mathrm{n}}$, was carried out as follows. The activated GC electrode with negative surface charges was treated with an aqueous solution of $1 \mathrm{wt} \%$ positively charged PDDA in $0.5 \mathrm{M} \mathrm{NaCl}$ for $20 \mathrm{~min}$. The electrode was washed with doubly distilled water and air dried, and was then soaked in the negatively charged MWCNT-PB suspension for $20 \mathrm{~min}$, followed by further rinsing and air drying. This corresponded to the formation of one bilayer of the PDDA/MWCNT-PB composite. Subsequent deposition of PDDA and MWCNT-PB layers can be obtained by repeating the layer-by-layer deposition procedures.

In a control experiment, PB particles were also prepared. $40.0 \mathrm{~mL}$ of $10 \mathrm{mM} \mathrm{FeCl}$ was reduced by a slightly excess amount of $\mathrm{H}_{2} \mathrm{O}_{2}$ to form ferrous ions. A solution containing $40.0 \mathrm{~mL}$ of $10 \mathrm{mM} \mathrm{K} \mathrm{K}_{3} \mathrm{Fe}(\mathrm{CN})_{6}$ containing $\mathrm{H}_{2} \mathrm{O}_{2}$ was added dropwise to the $\mathrm{FeCl}_{3}$ solution under stirring to form dispersed PB particles. The PB precipitate was collected and washed. ${ }^{33}$ $A$ very stable blue $\mathrm{PB}$ suspension was used to prepare the $\mathrm{LbL}$ multilayer PDDA-PB films following similar procedures.

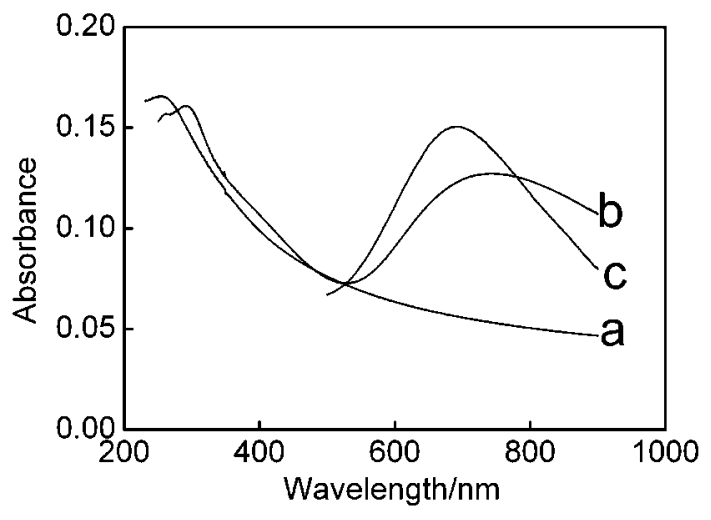

Fig. 1 UV-visible absorption spectra of (a) pure MWCNT, (b) MWCNT-PB composite, and (c) pure PB deposits.

\section{Results and Discussion}

\section{Deposition of Prussian blue (PB) on MWCNT surface}

When the aqueous suspension containing MWCNT was mixed with an acidic solution containing ferricyanide and $\mathrm{Fe}\left(\mathrm{NO}_{3}\right)_{3}$ in $0.1 \mathrm{M} \mathrm{KCl}$ ( $\mathrm{pH} 1.6$ ), spontaneous deposition of $\mathrm{PB}$ on the MWCNT material occurred immediately. The deposition process was allowed to proceed for $8 \mathrm{~h}$. No PB formation was observed without MWCNT. This implies that the MWCNT material played an important role in the formation of PB. The formation of $\mathrm{PB}$ can be described by the following reaction: ${ }^{34}$

$$
\mathrm{K}^{+}+\mathrm{Fe}^{2+}+\mathrm{Fe}(\mathrm{CN})_{6}^{3-}=\mathrm{KFeFe}(\mathrm{CN})_{6}
$$

This reaction shows that the ferric ions or ferricyanide ions should be firstly reduced to Fe(II) species. In the absence of any reducing agent, the reduction reaction should be promoted by the MWCNT materials. It has been reported that single-walled carbon nanotubes gave a redox potential of $+0.5 \mathrm{~V}$ (vs. SHE). ${ }^{35,36}$ The redox switching of the $\mathrm{Fe}^{3+} / \mathrm{Fe}^{2+}$ and $\mathrm{Fe}(\mathrm{CN}){ }^{3-14-}$ couples appeared at +0.77 and $+0.36 \mathrm{~V}(v s$. SHE $),{ }^{34}$ respectively. Therefore, only the ferric ions in solution were reduced by MWCNT, assuming that the redox potential of MWCNT was similar to that for single-walled carbon nanotubes. The PB materials deposited on the MWCNT surface were characterized by UV-visible absorption spectroscopy. As shown in Fig. 1(a), the absorption peak at $254 \mathrm{~nm}$ corresponded to the pure MWCNT deposits, consistent with reports in the literature. ${ }^{37}$ Figure 1(b) shows the absorption spectrum of the MWCNT-PB deposits. The absorption peak of the MWCNT materials shifted to $288 \mathrm{~nm}$, while the peak at $733 \mathrm{~nm}$ should correspond to the absorption of the intense charge transfer absorption band of the mixed valence PB deposits, ${ }^{34}$ as compared to the absorption band at $688 \mathrm{~nm}$ for the pure PB deposits (Fig. 1(c)). The changes in the MWCNT absorption band can be attributed to the change in the interfacial electron density at the MWCNT surface through interactions with the PB deposits. Experimental results confirmed the presence of PB deposits on the CNT materials.

The resulting MWCNT-PB composite was characterized by scanning electron microscopy. Figure 2(a) shows the SEM image of the purified MWCNT material with diameter of about $50 \mathrm{~nm}$, while the MWCNT-PB composite appears as much thicker tube with average diameter of $120 \mathrm{~nm}$ (Fig. 2(b)), indicating that a layer of PB was deposited homogeneously on the side-walls of the MWCNT material. In addition, the 


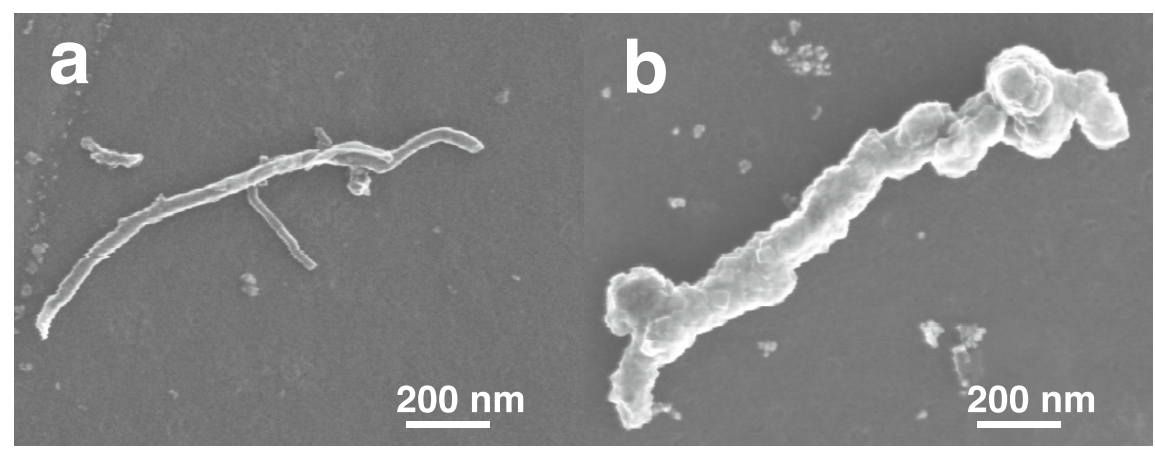

Fig. 2 SEM images of (a) pure MWCNT and (b) MWCNT-PB composite.

(a)

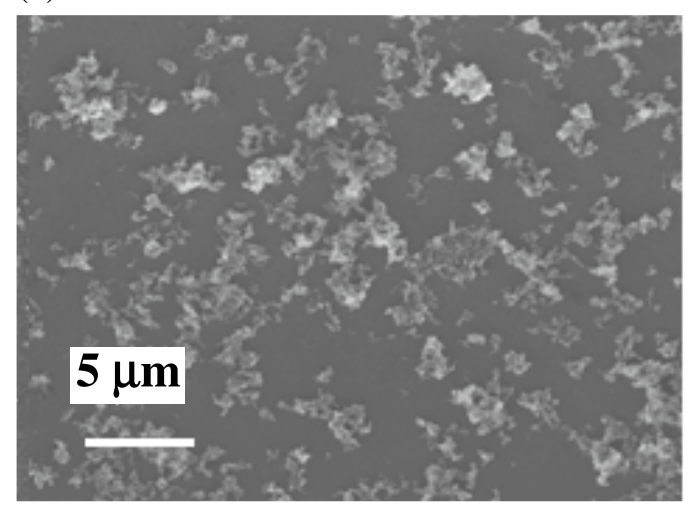

(b)

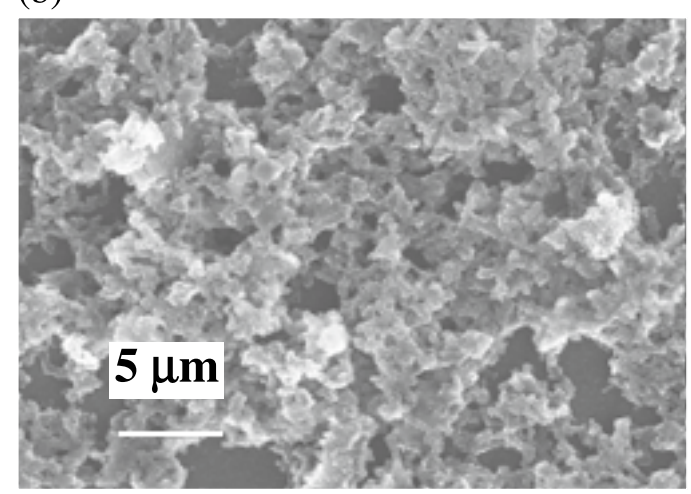

(c)

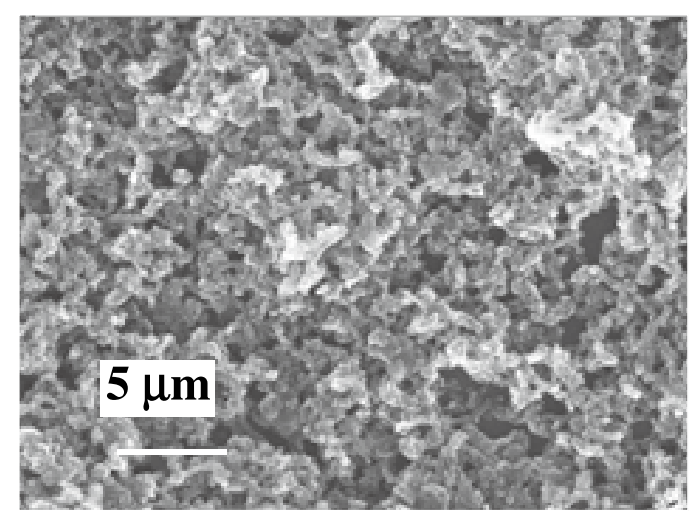

Fig. 3 SEM images of \{PDDA/MWCNT-PB $\}$ deposits on GC electrode under high amplification. (a) $\{\mathrm{PDDA} / \mathrm{MWCNT}-\mathrm{PB}\}_{1}$, (b) $\{\text { PDDA/MWCNT-PB }\}_{4}$ and (c) $\{\text { PDDA/MWCNT-PB }\}_{7}$
MWCNT-PB composite showed a narrow size distribution in length. The deposition of PB at the MWCNT material occurred in situ, indicating that the surface functional groups of the MWCNT material could act as favorite nucleation sites for the growth of PB. ${ }^{12}$ As a result, the PB deposits obtained would adhere to the walls of MWCNT tightly.

Characterization of the GC electrodes modified with MWCNT-PB composites

An activated GC electrode was alternately dipped in solutions containing positively charged PDDA and negatively charged MWCNT-PB composite for the layer-by-layer assembly of MWCNT-PB multilayers through electrostatic interactions. Figure 3(a) displays a typically high magnification SEM image of the substrate surface after the deposition of the first MWCNT-PB layer on the PDDA-coated substrate. The PB-deposited MWCNT showed an average length of $1-1.5 \mu \mathrm{m}$ and diameters of $115-125 \mathrm{~nm}$. Most of the MWCNT-PB deposits were in the form of single tubes. The SEM images of PDDA/MWCNT-PB multilayer deposits obtained by alternate deposition of PDDA and MWCNT-PB composites are also shown in Fig. 3. These SEM micrographs demonstrated that the loading of MWCNT-PB materials increased with the number of assembly layers. A three-dimensional MWCNT-PB network film with high functional density of $\mathrm{PB}$ can be obtained by this LbL technique. As shown in Fig. 3(c), a homogeneous $\{\text { PDDA/MWCNT-PB }\}_{7}$ multilayer was obtained after 7 alternate depositions of PDDA and MWCNT-PB layers.

The growth of the MWCNT-PB multilayer deposits on a quartz slide employing the LbL technique was also characterized by UV-visible absorption spectroscopy. Figure 4 shows the absorbance values as a function of the number of PDDA/MWCNT-PB layers. The absorption peak at $288 \mathrm{~nm}$ resulted from the absorption of the MWCNT material, while the absorption at $733 \mathrm{~nm}$ corresponded to that of $\mathrm{PB}$, as shown in the inset figure. Plots of the absorbance intensity of PB (solid circles) and MWCNT (solid squares) increased linearly with the number of multilayer deposits. This demonstrated that the film thickness could be easily controlled by the LbL technique. On the other hand, the assembly process was also monitored by cyclic voltammetry. Figure 5 shows the cyclic voltammograms of the GC electrode modified by multilayer $\{\text { PDDA/MWCNT-PB }\}_{n}$ deposits in a $0.1 \mathrm{M} \mathrm{K}_{2} \mathrm{SO}_{4}$ solution. The modified electrode showed typical redox peaks located at around $+0.17 \mathrm{~V}$ and $+0.90 \mathrm{~V}$ ( vs. $\mathrm{Ag} \mid \mathrm{AgCl})$, corresponding to the redox switching between Prussian white and PB and the switching between PB and Prussian yellow, respectively. The peak current for the reduction of PB to Prussian white located at $+0.17 \mathrm{~V}$ was used to monitor the assembly process. The cathodic peak current 


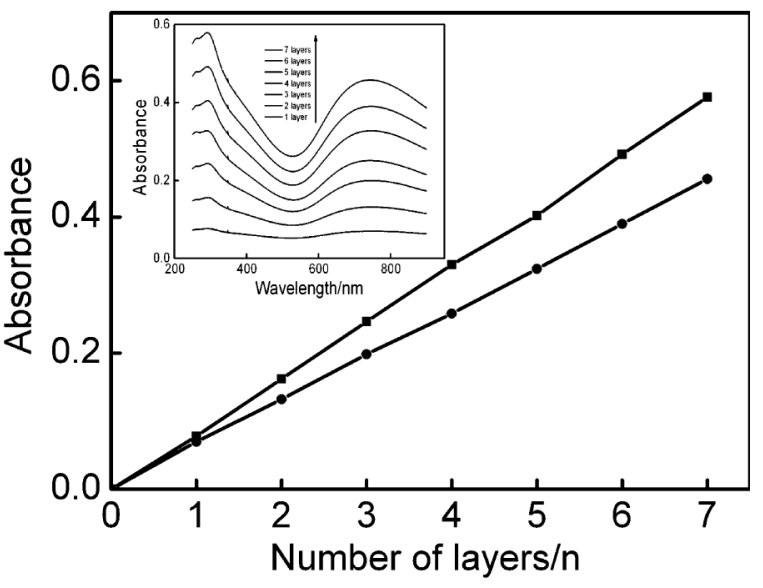

Fig. 4 A plot of the absorbance of MWCNT at $288 \mathrm{~nm}(\boldsymbol{\square})$ and PB at $733 \mathrm{~nm}(\bullet) v s$. the number of multilayer deposits. Insert shows the $\mathrm{UV}$-visible absorption spectra of the $\{\text { PDDA/MWCNT-PB }\}_{\mathrm{n}}$ deposits assembled on a quartz slide.

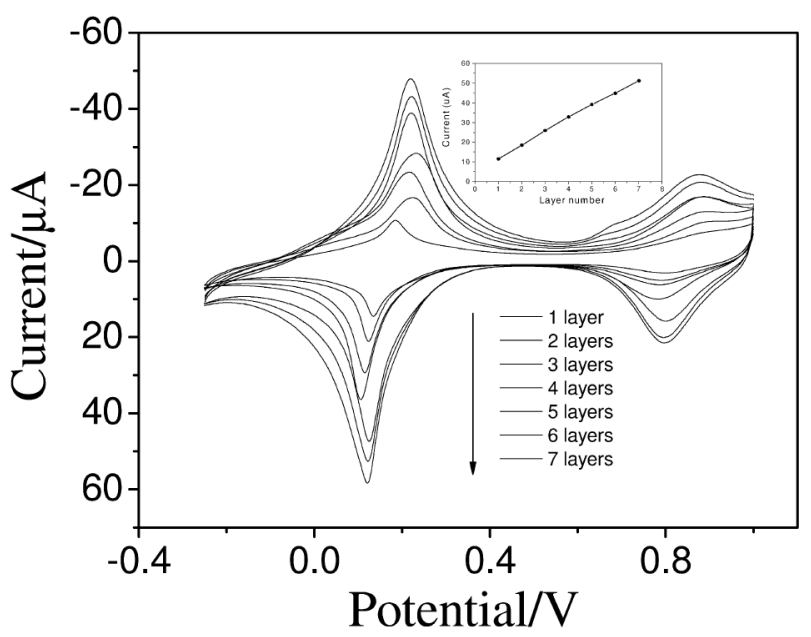

Fig. 5 Cyclic voltammograms of GC electrode with \{PDDA/MWCNT-PB $\}_{\mathrm{n}}$ multilayer deposits in $0.1 \mathrm{M} \mathrm{K}_{2} \mathrm{SO}_{4}$ at a scan rate of $50 \mathrm{mV} / \mathrm{s}$. The insert shows the cathodic peak current at around $+0.17 \mathrm{~V}$ as a function of the number of assembled layers.

increased linearly with the number of the assembly layers, indicating the increases in the PB coverage. A similar increase in PB coverage for multilayer deposition of the MWCNT-PB composites was also demonstrated by the absorption results shown in Fig. 4.

Electrocatalytic activity of the multilayer $\{P D D A / M W C N T-P B\}_{n}$ film toward the reduction of $\mathrm{H}_{2} \mathrm{O}_{2}$

The electrocatalytic activity of modified electrodes with MWCNT-PB deposits for the detection of $\mathrm{H}_{2} \mathrm{O}_{2}$ was examined at zero potential in stirred solutions. Figure 6 shows the amperometric responses for $\mathrm{H}_{2} \mathrm{O}_{2}$ at different modified electrodes recorded at a zero applied potential. The current traces for electrodes with one layer of MWCNT-PB deposits were much higher than the corresponding current responses at electrodes with MWCNT or one layer of PB deposits, that is $I_{\text {(MWCNT-PB) }}>I_{\mathrm{PB}} \gg I_{\text {MWCNT. }}$ An enhanced electrochemical response of $\mathrm{H}_{2} \mathrm{O}_{2}$ was observed at the $\mathrm{GC} /\{\mathrm{PDDA} / \mathrm{MWCNT}-\mathrm{PB}\}$ composite electrode, indicating the possible synergetic effects ${ }^{22}$

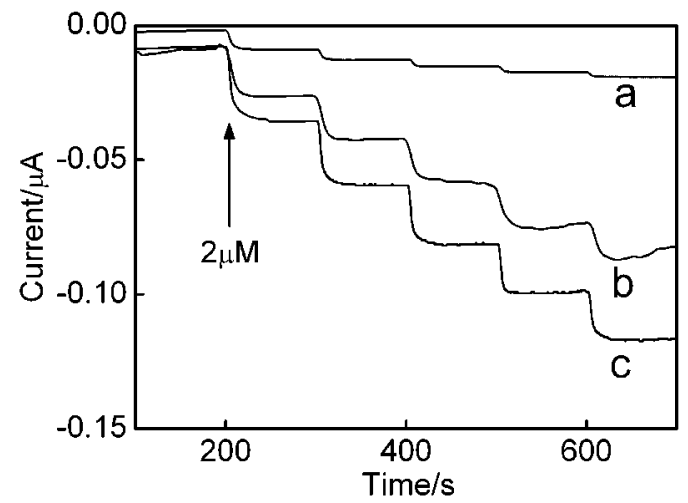

Fig. 6 Amperometric responses of $\mathrm{H}_{2} \mathrm{O}_{2}$ in $0.1 \mathrm{M} \mathrm{KCl}$ at a zero detection potential. (a) GC/MWCNT, (b) GC/\{PDDA/PB $\}_{1}$, and (c) GC/\{PDDA/MWCNT-PB $\}_{1}$ electrodes.

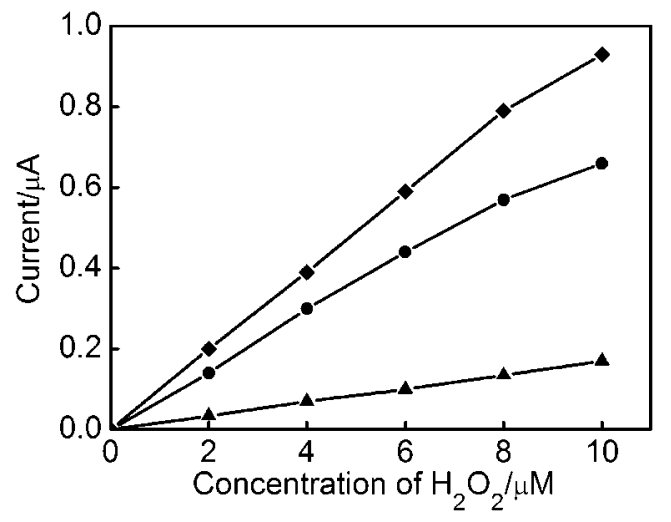

Fig. 7 Calibration curves for $\mathrm{H}_{2} \mathrm{O}_{2}$ detection at $\mathrm{GC} /\{\mathrm{PDDA} /$ MWCNT-PB $\}_{\mathrm{n}}$ electrodes in a $0.1 \mathrm{M} \mathrm{KCl}$ solution at zero potential. $n=1(\bullet), 4(\bullet)$ and $7(\bullet)$.

when both MWCNT and PB were present. Additionally, the PDDA/MWCNT-PB modified electrodes also offered a fast amperometric response to the addition of $\mathrm{H}_{2} \mathrm{O}_{2}$.

Multilayer $\{P D D A / M W C N T-P B\}_{n}$ films for sensitive $\mathrm{H}_{2} \mathrm{O}_{2}$ detection

Figure 7 shows the amperometric response of $\mathrm{H}_{2} \mathrm{O}_{2}$ at electrodes with different number of $\{\text { PDDA/MWCNT-PB }\}_{n}$ multilayers at a zero detection potential. The response current observed at the modified electrode with 7 layers of \{PDDA/MWCNT-PB\} composites for $8.0 \mu \mathrm{M} \quad \mathrm{H}_{2} \mathrm{O}_{2}$ was approximately $0.80 \mu \mathrm{A}$, much higher than the corresponding current observed for a modified electrode with a lower number of $\{$ PDDA/MWCNT-PB $\}$ composites. It is obvious that good linearity was observed for all the electrodes examined, typically up to $10 \mu \mathrm{M}$ of $\mathrm{H}_{2} \mathrm{O}_{2}$. The detection sensitivity increased with increasing number of assembly layers. Modified electrodes with 1, 4 and 7 multilayers of \{PDDA/MWCNT-PB $\}$ composites showed detection sensitivity values of $0.14,0.53,0.83 \mathrm{~mA}$ $\mathrm{M}^{-1} \mathrm{~cm}^{-2}$, respectively. The results demonstrated that the detection sensitivity of the sensor could be easily improved by increasing the functional density of MWCNT-PB deposits. In addition, the relative standard deviation (RSD) for 5 replicate measurements of $2 \mu \mathrm{M} \mathrm{H}_{2} \mathrm{O}_{2}$ with a GC/\{PDDA/MWCNT-PB $\}_{7}$ electrode was $5.6 \%$, indicating a good stability for sensing $\mathrm{H}_{2} \mathrm{O}_{2}$. 


\section{Conclusions}

A multi-walled carbon nanotube-Prussian blue composite material has been prepared, through deposition of Prussian blue on surface nucleation sites of the carbon nanotubes. The MWCNT-PB composite can be assembled on glassy carbon electrodes with poly(diallyldimethylammonium chloride) in a simple and controlled way by the layer-by-layer assembly technique. The resulting $\{\mathrm{PDDA} / \mathrm{MWCNT}-\mathrm{PB}\}_{\mathrm{n}}$ multilayer showed sensitive detection toward the catalytic reduction of hydrogen peroxide. The present approach provides a novel way for the fabrication of biosensors with high sensitivity and stability.

\section{Acknowledgements}

This work was partially supported by the Research Grants Council of Hong Kong (HKBU 201804P), the Natural Science Foundation of Shaanxi Province in China (No. 2009JM2004) and Scientific Research Plan Projects of Shaanxi Provincial Department of Education (No. 09JK756).

\section{References}

1. A. Rodney, J. David, Q. Dali, and R. Terry, Acc. Chem. Res., 2002, 35, 1008.

2. R. H. Baughman, A. Zakhilov, and W. A. de Heer, Science, 2002, 297, 787.

3. C. N. Rao, B. C. Satishkumar, A. Govindaraj, and M. Nath, ChemPhysChem, 2001, 2, 78.

4. H. Dai, Surf. Sci., 2002, 500, 218.

5. W. A. de Heer, A. Chatelain, and D. Ugarte, Science, 1995, $270,1179$.

6. S. J. Tans, R. M. Verschueren, and C. Dekker, Nature, 1998 , $393,49$.

7. H. Dai, J. H. Hafner, A. G. Linzler, D. T. Colbert, and R. E. Smally, Nature, 1996, 384, 147.

8. J. Wang and M. Musameh, Anal. Chem., 2003, 75, 2075.

9. E. Katz and I. Willner, ChemPhysChem, 2004, 5, 1084.

10. J. Wang, M. Musameh, and Y. H. Lin, J. Am. Chem. Soc., 2003, 125, 2408.

11. M. N. Zhang, Y. M. Yan, K. P. Gong, L. Q. Mao, Z. X. Guo, and Y. Chen, Langmuir, 2004, 20, 8781.

12. Y. H. Lin, X. L. Cui, and X. R. Ye, Electrochem. Commun., 2005, 7, 267.
13. T. Matsumoto, T. Komatsu, K. Arai, T. Yamazaki, M. Kijima, H. Shimizu, Y. Takasawab, and J. Nakamura, Chem. Commun., 2004, 7, 840.

14. Y. L. Yao, Y. Ding, L. S. Ye, and X. H. Xia, Carbon, 2006, $44,61$.

15. M. G. Zhang and W. Gorski, J. Am. Chem. Soc., 2005, 127, 2058.

16. L. Gorton, Electroanalysis, 1995, 7, 23.

17. A. A. Karyakin, E. E. Karyakina, and L. Gorton, Anal. Chem., 2000, 72, 1720.

18. L. V. Lukachova, E. A. Kotel'nikova, D. D'Ottavi, E. A. Shkerin, E. E. Karyakina, D. Moscone, G. Palleschi, A. Curulli, and A. A. Karyakin, Bioelectrochemistry, 2002, 55, 145.

19. D. Zhang, K. Zhang, Y. L. Yao, X. H. Xia, and H. Y. Chen, Langmuir, 2004, 20, 7303.

20. D. Zhang, K. Wang, D. C. Sun, X. H. Xia, and H. Y. Chen, Chem. Mater., 2003, 15, 4163.

21. Y. L. Hu, J. H. Yuan, W. Chen, K. Wang, and X. H. Xia, Electrochem. Commun., 2005, 7, 1252.

22. J. Li, J. D. Qiu, J. J. Xu, H. Y. Chen, and X. H. Xia, $A d v$. Funct. Mater., 2007, 17, 1574.

23. Z. X. Jin, X. Sun, G. Q. Xu, S. H. Goh, and W. Ji, Chem. Phys. Lett., 2000, 318, 505.

24. Y. J. Zou, L. X. Sun, and F. Xu, Biosens. Bioelectron., 2007, 22, 2669.

25. Y. J. Zou, L. X. Sun, and F. Xu, Talanta, 2007, 72, 437.

26. Z. F. Li, J. H. Chen, W. Li, K. Chen, L. H. Nie, and S. Z. Yao, J. Electroanal. Chem., 2007, 603, 59.

27. X. Zhang and J. C. Shen, Adv. Mater., 1999, 11, 1139.

28. J. H. Rouse and P. T. Lillehei, Nano Lett., 2003, 3, 59.

29. A. Jaiswal, J. Colins, B. Agricole, P. Delhaes, and S. Ravaine, J. Colloid Interface Sci., 2003, 261, 330.

30. D. M. DeLongchamp and P. T. Hammond, Chem. Mater. 2004, 16, 4799.

31. P. A. Fiorito, V. R. Goncales, E. A. Ponzio, and S. I. Córdoba de Torresi, Chem. Commun., 2005, 3, 366.

32. K. Shi and K. K. Shiu, Anal. Chem., 2002, 74, 879.

33. S. Q. Liu, J. J. Xu, and H. Y. Chen, Electrochem. Commun., 2002, 4, 421.

34. K. Itaya, I. Uchida, and V. D. Neff, Acc. Chem. Res., 1986, 19, 162.

35. H. C. Choi, M. Shim, S. Bangsaruntip, and H. Dai, J. Am. Chem. Soc., 2002, 124, 9058.

36. L. Qu and L. Dai, J. Am. Chem. Soc., 2005, 127, 10806.

37. J. Chen, M. A. Hamon, H. Hu, Y. Chen, A. M. Rao, P. C. Eklund, and R. C. Haddon, Science, 1998, 282, 95. 